\title{
Open Data in the Governance of South African Higher Education
}

\section{Primary research question}

What is the level of use and possible impact of open data in the governance of South African higher education?

\section{Secondary research question}

What is the role of intermediaries in the supply and use of open data in the governance of South African higher education?

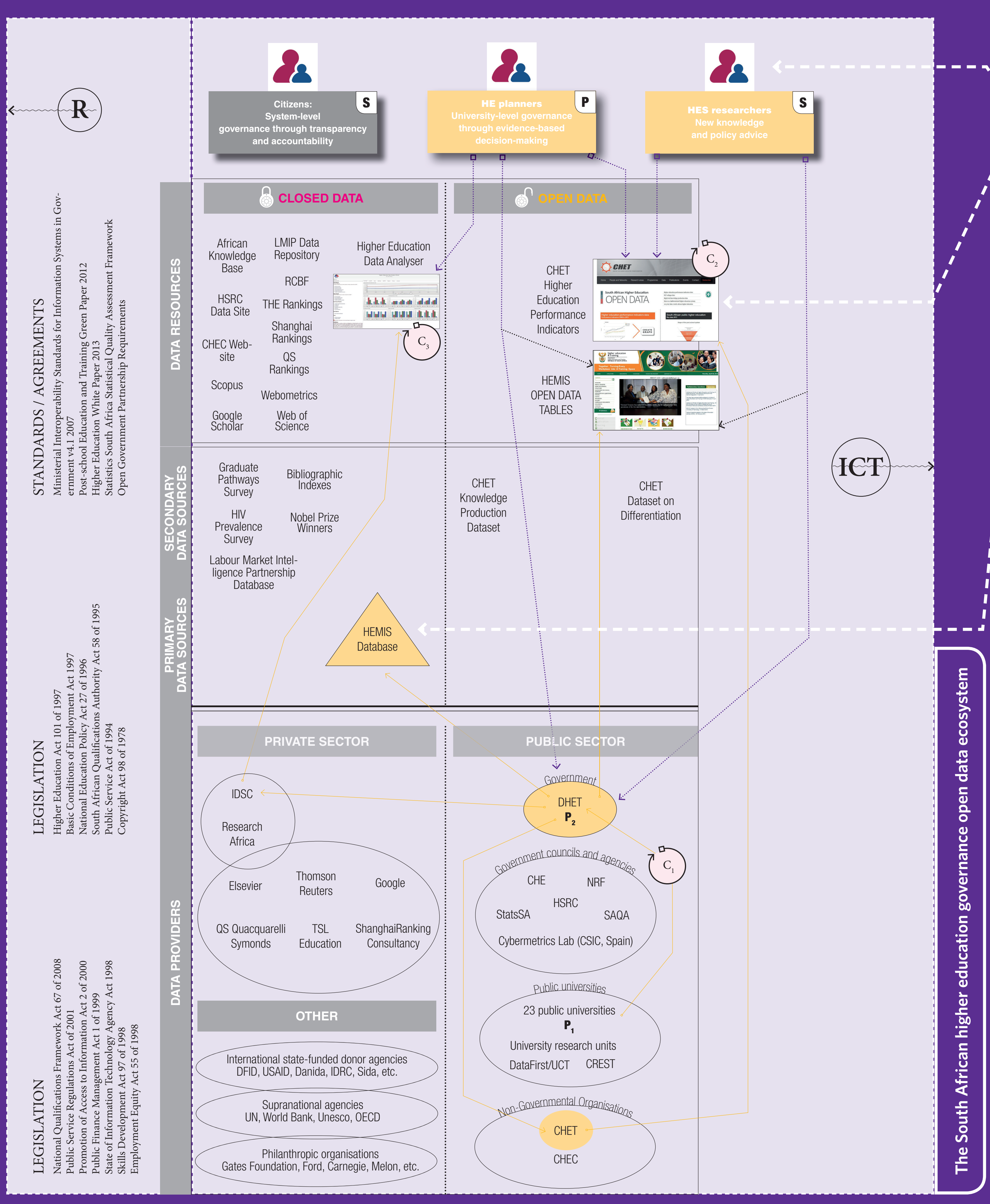

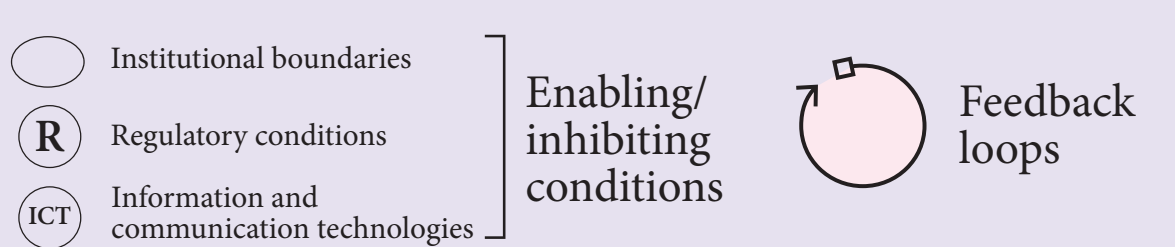

Background

The Centre for Higher Education Transformation

(CHET) is a non-governmental organisation that

institutional and systemic levels.

CHET's research focuses on issues of
university governance, performance indicators,

differentiation knowledge production and the

by the university execulive and the university's

institutional planning unit.

The Department for Higher Education and

Method (DHET) is the South African government (D)

CHET Open Data Platform

www.chet.org za/sahe-open-data Data collection

Semi-structured interviews with data users and the primary

Data users
University planners (institutional-level policy)

University planners (institutional-level policy)

Higher education studies (HES) researchers (national policy)

albeit infrequently. Researchers expressed the need for richer da

Recommendation: CHET should take note of these findings when planning

Primary data provider

Government (Department for Higher Education and Training)

Primary data source \&

differentiated role for itself based the needs of different user groups and given

HEMIS is an isolated data source. Granting access to HEMIS by third-

(D)

parties (under controlled conditions to protect personal data) could furthe
stimulate the evolution of the open data ecosystem and relieve presse

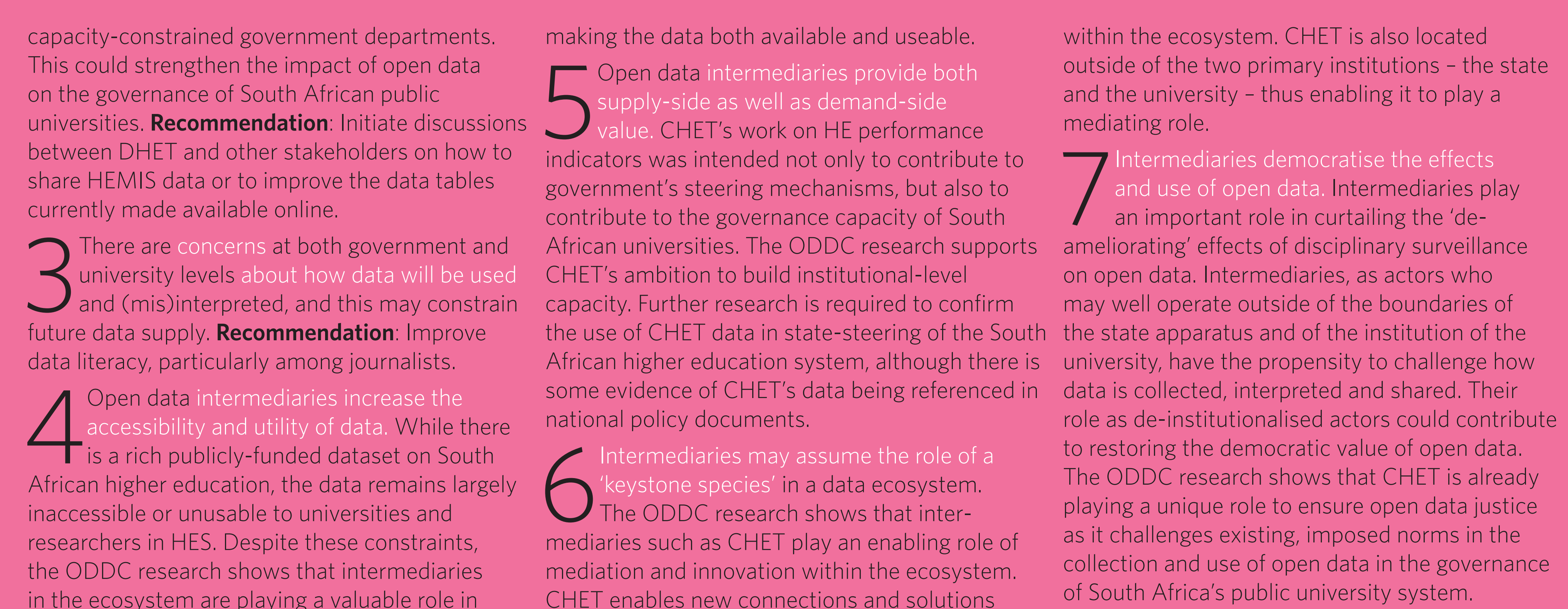

Conclusions

The HE governance open data ecosystem has evolved despite poor data provision by government because of the presence of intermediaries in the ecosystem.
By providing a richer information context o Increasing the fluidity of government and/or by making the data interoperable, open data could remove uncertainties government could improve the uptake of around both the degree of access data by new users and intermediaries, as provided by intermediaries and the well as by the existing intermediaries. financial sustainability of the open 